\title{
Role of Reactive Oxygen Species and Nitric Oxide in Mediating Chemotherapeutic Drug Induced Bystander Response in Human Cancer Cells Exposed In-Vitro
}

\author{
Mani Chinnadurai ${ }^{\mathrm{a}}$, Bhavna S Rao ${ }^{\mathrm{a}}$, Ramasamy Deepika ${ }^{\mathrm{a}}$, Solomon F. D. Paul ${ }^{\mathrm{a}}$, \\ Perumal Venkatachalam ${ }^{\mathrm{a}, \mathrm{b}}$
}

\begin{abstract}
Background: The intention of cancer chemotherapy is to control the growth of cancer cells using chemical agents. However, the occurrence of second malignancies has raised concerns, leading to re-evaluation of the current strategy in use for chemotherapeutic agents. Although the mechanisms involved in second malignancy remain ambiguous, therapeutic-agent-induced non-DNA targeted effects like bystander response and genomic instability cannot be eliminated completely. Hence, Bleomycin (BLM) and Neocarzinostatin (NCS), chemotherapeutic drugs with a mode of action similar to ionizing radiation, were used to study the mechanism of bystander response in human cancer cells (A549, CCRF-CEM and HL-60) by employing co-culture methodology.
\end{abstract}

Methods: Bystander effect was quantified using micronucleus $(\mathrm{MN})$ assay and in-situ immunofluorescence $(\gamma \mathrm{H} 2 \mathrm{AX}$ assay). The role of reactive oxygen species (ROS) and nitric oxide (NO) in mediating the bystander response was explored by pre-treating bystander cells with dimethylsulphoxide (DMSO) and C-PTIO respectively.

Results: Bystander response was observed only in CCRF-CEM and A549 cells $(\mathrm{P}<0.001)$. A significant decrease in this response was observed with ROS scavenger, DMSO.

Manuscript accepted for publication March 23, 2012

${ }^{\mathrm{a} D e p a r t m e n t ~ o f ~ H u m a n ~ G e n e t i c s, ~ C o l l e g e ~ o f ~ B i o m e d i c a l ~ S c i e n c e ~}$ Technology and Research, Sri Ramachandra University, Porur, Chennai, India

${ }^{\mathrm{b}}$ Corresponding author: Perumal Venkatachalam.

Email: venkip@yahoo.com

doi:10.4021/wjon474w
Conclusions: This significant attenuation in the bystander response on treatment with DMSO, suggests that ROS has a more significant role in mediating the bystander response. Since the possibility of the ROS and NO in mediating these bystander effect was confirmed, mechanistic control of these signaling molecules could either reduce radiation damage and potential carcinogenicity of normal tissues (by reducing bystander signaling) or maximize cell sterilization during chemotherapy (by amplifying bystander responses in tumors).

Keywords: Bystander effect; Bleomycin; Neocarzinostatin; Reactive oxygen species; Nitric oxide; Micronucleus assay

\section{Introduction}

There is now an extensive body of evidence for the spatial and temporal transmission of adverse effects from irradiated cells to un-irradiated "bystander" cells, and the phenomenon is termed as bystander response. Bystander effects were found to increase genomic instability and reduce cell survival in un-irradiated cells. This calls for re-evaluation of therapeutic strategies in order to obtain better response and reduce the risk of therapy associated second tumors.

Studies have shown that radiation-induced bystander effects are mediated either through transmission of certain biomolecules and/or molecular signals either by intercellular communication through gap junctions [1] or by release of soluble factors into the culture medium [2]. Even though molecules like reactive oxygen species (ROS) [3], interleukin 8 [4], transforming growth factor beta (TGF $\beta$ ) [5], tumor necrosis factor $\alpha$ (TNF $\alpha)$ [6], tumor necrosis factors related apoptosis inducing ligand (TRAIL), 5-hydroxytryptamine, L-DOPA, glycine, or nicotine $[7,8]$ and nitric oxide (NO) [9] have been shown to mediate radiation-induced bystander effects; the mechanism is yet to be identified. Similarly, signaling pathways of cyclooxygenase-2 (COX-2) [10] and Nuclear Factor KappaB (NFkB) [11] have been shown to be involved in mediating bystander responses.

Emerging literature has shown that cancer chemotherapeutic drugs like mitomycin [12], actinomycin [13] and 
bleomycin [14] can also induce bystander response and genomic instability [15] in unexposed neighboring cells similar to ionizing radiations. In line with these results, mitomycin $\mathrm{C}$ and phleomycin induce normal human B-lymphoblastoid cells to produce medium soluble factors that elicit bystander effects in unexposed cells [12]. Molecular players involved in mediating radiation and chemical induced bystander response are diverse and may depend on the cell type or its physiological state and genotoxic agent used. Similar to radiation-induced bystander response, the mediator of the chemotherapeutic bystander effect has not been identified yet but is of potential therapeutic interest. Although ROS and NO were shown to be the mediators of chemotherapeutic drug, bleomycin(BLM) induced bystander response in normal cells (human mesenchymal stem cells and peripheral blood lymphocytes)[14], the real players in the case of cancer cells are yet to be identified. Hence it was of interest to investigate the role of ROS and NO in mediating the bystander response induced by chemotherapeutic drugs, BLM and neocarzinostatin (NCS) in human cancer cells namely A549 (lung adenocarcinoma), CCRF-CEM (T-lymphoblast like) and HL-60 (Human leukemia) cells.

\section{Materials and Methods}

\section{Maintenance of cell lines}

The cell lines used, namely, A549, CCRF-CEM and HL-60, obtained from NCCS, Pune, were maintained and grown in a humidified incubator at $37^{\circ} \mathrm{C}$ with $5 \% \mathrm{CO}_{2}$. While the A549 cells were grown as a monolayer in plastic tissue culture flasks (p24 to p38) in Dulbecco's Modified Eagles Medium (DMEM) (GIBCO, Grand Island, New York, USA), HL-60 (p6 to p12) and CCRF-CEM (p8 to p12) cells were grown as suspension cultures in Minimum Essential Medium (MEM) (GIBCO, Grand Island, New York, USA). The media was supplemented with 10\% fetal bovine serum (FBS) (GIBCO, Grand Island, New York, USA) and antibiotics (Penicillin 50 $\mathrm{IU} / \mathrm{mL}$, Streptomycin $35 \mu \mathrm{g} / \mathrm{mL}$ and Gentamycin $2.5 \mu \mathrm{g} / \mathrm{mL}$ ) (GIBCO, Grand Island, New York, USA).

\section{Co-culture of BLM and NCS exposed cells with unex- posed cells}

Approximately $1 \times 10^{5}$ cells were seeded onto commercially available transwell culture inserts (Thincert ${ }^{\mathrm{TM}}$, Greiner Bio one, Germany) and an equal number of cells were seeded into six well plates. This was incubated at $37^{\circ} \mathrm{C}$ for 24 hours. After 24 hours, the cells in the thincert were exposed to the drug BLM (Dabur, Solan, India) at concentrations of 40 and $80 \mu \mathrm{g} / \mathrm{mL}$ for 3 hours and NCS (Sigma, Rehovot, Central District, Israel) at concentrations of 0.5 and $2 \mu \mathrm{g} / \mathrm{mL}$ for 1 hour. A set of controls was used. Following exposure, the drug treated cells were washed thrice with their respective media. The cells in the thincerts (directly exposed) and in the six well plates (unexposed or bystander) were co-cultured using the methodology described by Geraschenko and Howell [16].

\section{Analysis of DNA damage using micronucleus (MN) assay}

Following co-culture, $1 \times 10^{5}$ directly exposed and bystander cells were seeded onto p60 plates and cultured in their respective media with $10 \%$ FBS and cytochalasin-B $(3 \mu \mathrm{g} / \mathrm{mL})$ (Sigma, Bellefonte, USA) to arrest cells at the cytokinesis stage at $37^{\circ} \mathrm{C}$ in a $5 \% \mathrm{CO}_{2}$ incubator. The adherent cells were harvested after 72 hours and the suspension cultures after 48 hours. For suspension cultures, the cells were subject to a brief treatment with hypotonic solution $(0.45 \% \mathrm{KCl})$ and fixed with methanol and acetic acid in the ratio $3: 1$. The cells were dropped on cold glass slides, stained with $10 \%$ Giemsa solution ( $\mathrm{pH}$ 6.8, GIBCO, Burlington, USA) and analysed under a light microscope. The adherent cells were washed with phosphate buffer saline (PBS), fixed with icecold methanol and air dried after 72 hours of incubation. The cells were stained with diamino-phenyle-indole (DAPI) (VysisInc, Downers Grove, USA) and visualized using a fluorescence microscope.

Binucleated cells (cells with two daughter nuclei surrounded by cytoplasm) were scored for the presence of $\mathrm{MN}$ according to the scoring criteria given by Fenech et al [17]. Based on the recorded data, the frequency of $\mathrm{MN}(\mathrm{MNi})$ was calculated using the formula $\mathrm{MNi}=\mathrm{a} / \mathrm{b}$ and the error was calculated by $\mathrm{MNi}=\sqrt{ } \mathrm{a} / \mathrm{b}$ where ' $\mathrm{a}$ ' is the total number of micronuclei and ' $b$ ' is the total number (1000) of binucleate cells scored.

\section{Quantification of bystander effect by in-situimmuno-flu- orescence assay}

Following co-culture, about $1 \times 10^{6}$ directly exposed and bystander cells were taken in separate tubes for flow cytometric evaluation of $\gamma \mathrm{H} 2 \mathrm{AX}$ and COX-2. The cells were fixed with $2 \%$ paraformaldehyde and ice-cold methanol, and made permeable by treatment with $1 \%$ Triton X-100. The cells were blocked in $1 \%$ Bovine Serum Albumin (BSA) for 1 hour, washed and incubated at $4{ }^{\circ} \mathrm{C}$ overnight with primary antibody for $\gamma \mathrm{H} 2 \mathrm{AX}$ and COX-2 (Abcam, Ab 1431-100 and Ab 90345, respectively). After overnight incubation, the cells were washed to remove excess primary antibody and incubated with the respective FITC labeled secondary antibody (Abcam, Ab 6717 and $\mathrm{Ab} 6785$ respectively) for $1 \mathrm{hr}$ at 37 ${ }^{\circ} \mathrm{C}$ in the dark. Flow cytometry measurement was done using a FACS Calibur (Becton Dickinson Systems) and 10,000 events were analyzed using Cell Quest software. The relative FITC fluorescence intensities were calculated by taking the ratio of the histograms representing exposed cells and con- 

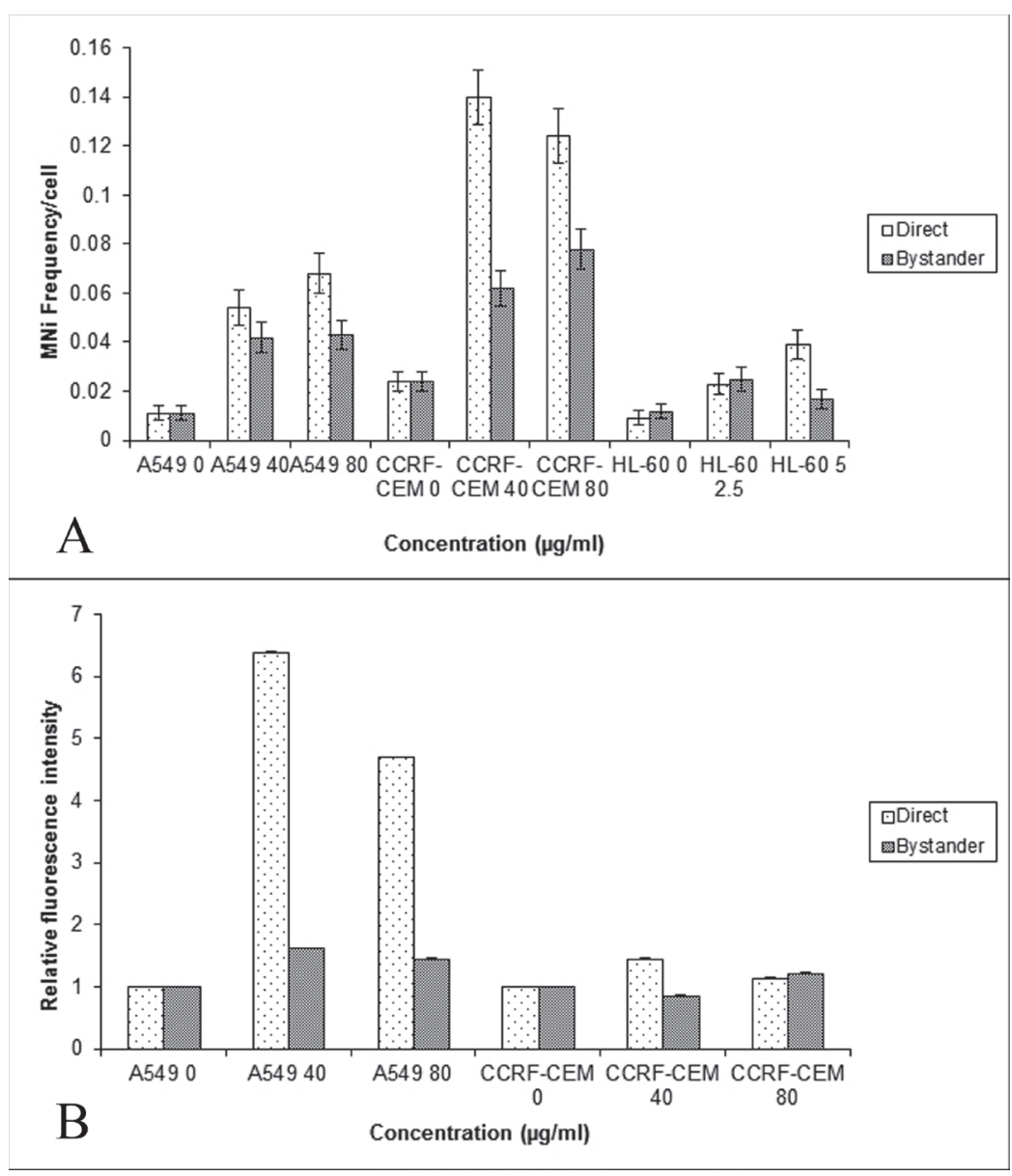

Figure 1. Comparison of the MN frequency in the A549, CCRF-CEM and HL-60 cells (A) and $\mathrm{YH} 2 \mathrm{AX}$ relative fluorescent intensity (B) obtained using flow cytometry in the A549 and CCRF-CEM cells that are exposed to BLM and then co-cultured with their respective bystander cells for $24 \mathrm{hrs}$. Each bar represents the mean \pm SE of the frequency of micronuclei and relative fluorescence intensity induced for three independent experiments $(n=3)$.

trol cells [18].

\section{Effect of Dimethyl sulphoxide (DMSO) and C-PTIO on bystander cells}

As DMSO and C-PTIO are known scavengers of ROS and $\mathrm{NO}$, respectively, the role of ROS and NO in mediating the drug induced bystander effect was studied. Prior to co-culture of directly exposed and unexposed cells, the unexposed cells were pretreated with $10 \mathrm{mM}$ DMSO (Sigma, USA) or $20 \mu \mathrm{M}$ C-PTIO (Sigma, USA) respectively for an hour and the DNA damage was measured using MN assay.

\section{Statistical analysis}

The differences in the $\mathrm{MN}$ frequencies and relative fluorescence intensity ratios within and between the treatment groups for each cell type were compared. As all experiments were repeated thrice $(n=3)$, the average of the assimilated data was compared by the paired t-test and one-way analysis of variance (ANOVA) using the INSTAT programme.

\section{Results}

\section{Analysis of DNA damage in BLM exposed and bystander cells using $\mathrm{MN}$ and $\gamma \mathrm{H} 2 \mathrm{AX}$ assay}

Baseline $\mathrm{MN}$ frequencies obtained in the direct control cells of A549, CCRF-CEM and HL-60 cells were $0.011 \pm 0.003$, $0.024 \pm 0.004$, and $0.009 \pm 0.003$ respectively (standard errors of the mean (SEM) for $n=3$ ). Of the three cell lines used, the CCRF-CEM lymphoblast like cells had a higher base line $\mathrm{MN}$ frequency. No variation was observed in the baseline $\mathrm{MN}$ frequencies of direct and bystander control cells. The various cell types (A549, CCRF-CEM and HL-60 cells) used in the study were exposed to a concentration of 40 and $80 \mu \mathrm{g} / \mathrm{mL}$ BLM for three hours and the DNA dam- 


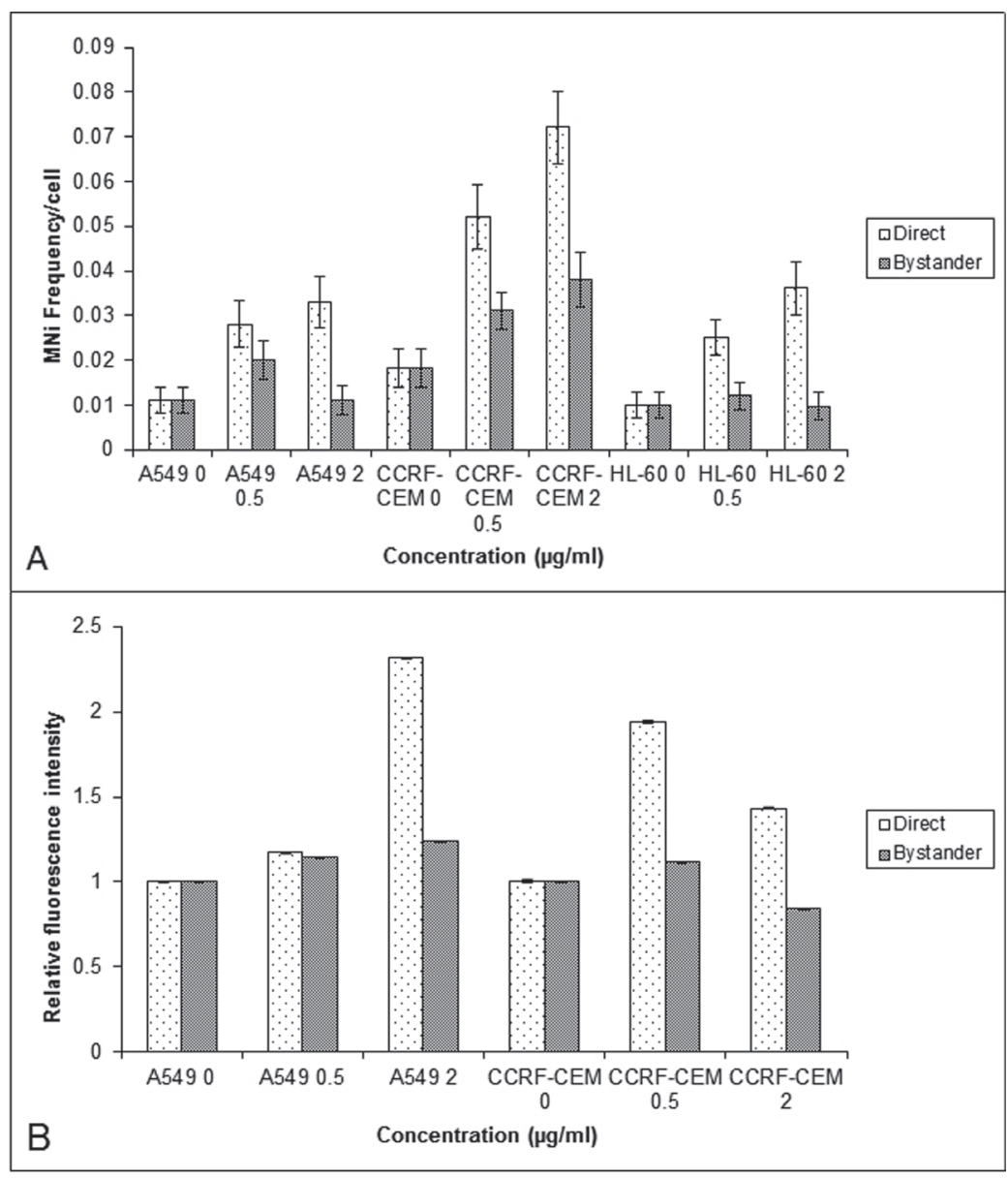

Figure 2. Comparison of the MN frequency in the A549, CCRF-CEM and HL-60 cells (A) and $\mathrm{YH} 2 \mathrm{AX}$ relative fluorescent intensity (B) obtained using flow cytometry in the A549 and CCRF-CEM cells that are exposed to NCS and then co-cultured with their respective bystander cells for $24 \mathrm{hrs}$. Each bar represents the mean \pm SE of the frequency of micronuclei and relative fluorescence intensity induced for three independent experiments $(n=3)$.

age was quantified using the MN assay and $\gamma \mathrm{H} 2 \mathrm{AX}$ assay. The obtained results are provided in Figure 1. When HL-60 cells were exposed to 40 and $80 \mu \mathrm{g} / \mathrm{mL}$ of BLM, the cells underwent apoptosis (data not shown). Hence the concentration of BLM was reduced to 2.5 and $5 \mu \mathrm{g} / \mathrm{ml}$ and then used for co-culture experiments. The result showed that BLM treatment induced a significant increase in the MN frequency $(\mathrm{P}<0.001)$ in A549, CCRF-CEM and HL-60 cells (Fig.1A). However, only bystander A549 and CCRF-CEM cells showed a significantly $(\mathrm{P}<0.001)$ higher $\mathrm{MN}$ frequency when compared to their respective controls, but the induced $\mathrm{MN}$ frequency did not show any dose dependency. Thus, the observed higher frequency of MN in the bystander cells suggests that the BLM induced bystander effect is similar to ionizing radiation and concentration independent. HL-60 cells showed an increased MN frequency in the cells directly exposed to BLM. But in the bystander cells, only the bystander $40 \mu \mathrm{g} / \mathrm{mL}$ showed increased $\mathrm{MN}$ frequency when compared to its control.
As the co-cultured bystander cells of A549 and CCRFCEM cells alone showed enhanced DNA damage as measured by the MN assay, the bystander response was further examined in these cell lines by quantifying another marker of DNA damage, the $\gamma \mathrm{H} 2 \mathrm{AX}$ foci. The $\gamma \mathrm{H} 2 \mathrm{AX}$ assay showed an increase in the fluorescence intensity in both directly exposed $(\mathrm{P}<0.001)$ and bystander cells of $\mathrm{A} 549$, and in the bystander cells of $80 \mu \mathrm{g} / \mathrm{mL}$ CCRF-CEM (Fig. 1B); further confirming that BLM exposure could induce bystander response in unexposed A549 and CCRF-CEM cells.

\section{Analysis of DNA damage in NCS exposed and bystander cells using MN and $\gamma \mathrm{H} 2 \mathrm{AX}$ assay}

The study of BLM induced bystander effect, observed in A549, CCRF-CEM and HL-60 was extended further by using another radiomimetic drug, NCS. NCS induced DNA damage was measured using the MN (Fig. 2A) and $\gamma \mathrm{H} 2 \mathrm{AX}$ assays (Fig. 2B). In A549 and CCRF-CEM, the MN frequen- 


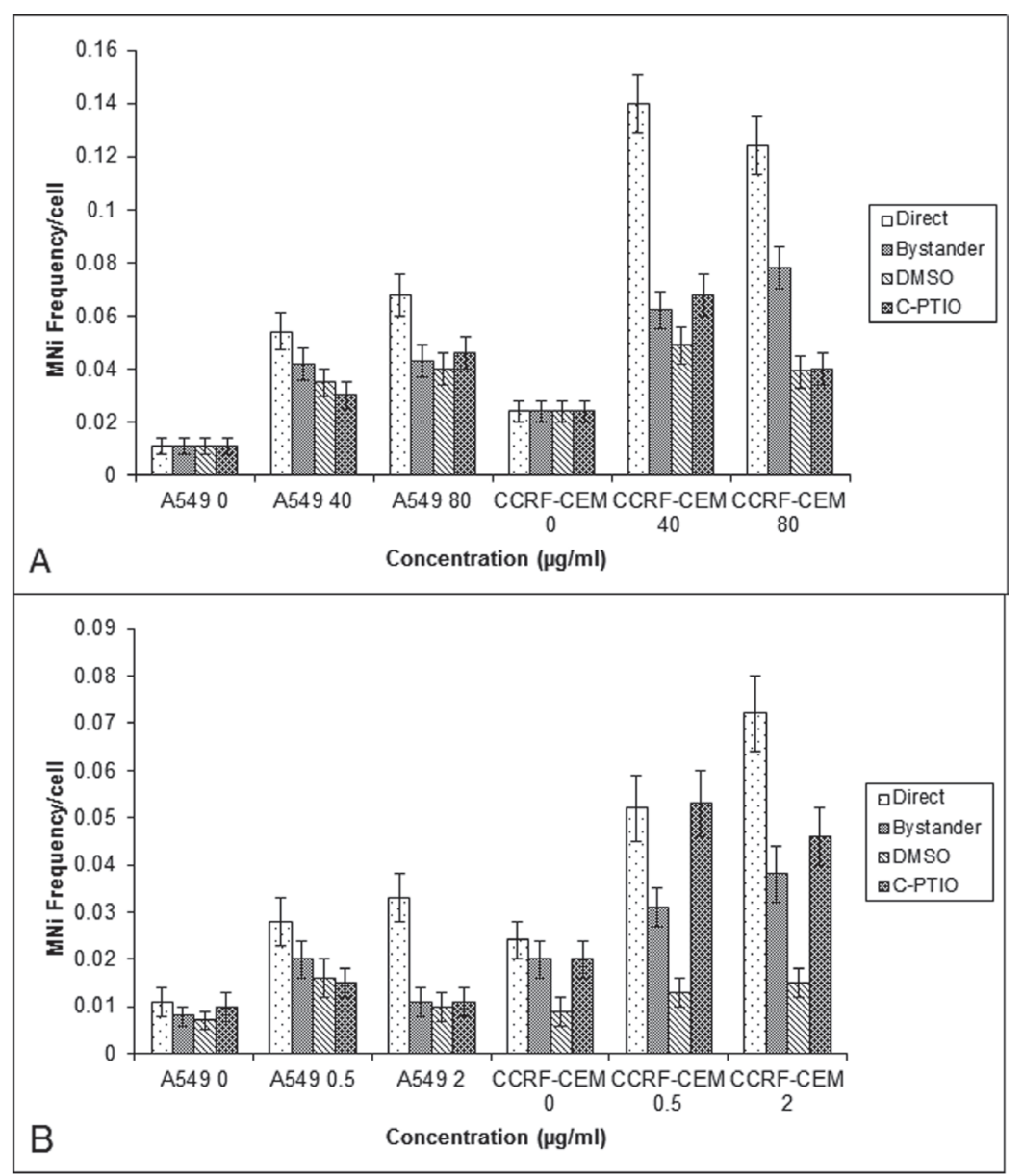

Figure 3. MN frequency obtained in the A549 and CCRF-CEM cells that are exposed to BLM (A) or NCS (B) and then co-cultured with their respective bystander cells for $24 \mathrm{hrs}$ with and without DMSO or C-PTIO. Each bar represents the mean \pm SE of the frequency of micronuclei induced for three independent experiments $(n=3)$.

cy of directly exposed and bystander cells were significantly higher $(\mathrm{P}<0.05)$ than their respective controls. However in HL-60, the MN frequency showed a significant increase only in directly exposed cells $(\mathrm{P}<0.05)$ indicating the absence of NCS bystander response in HL-60 leukemic cells (Fig. 2A).

$\gamma \mathrm{H} 2 \mathrm{AX}$ evaluation showed an increase in the fluorescence intensity in directly exposed as well as the bystander cells of A549, and in the bystander cells of $40 \mu \mathrm{g} / \mathrm{mL}$ CCRF$\operatorname{CEM}(\mathrm{P}<0.01)$ (Fig. 2B).

\section{Effect of ROS and NO scavengers in mediating the by- stander effect}

Since it has been suggested that ROS and NO are involved in mediating radiation induced bystander response [19], its role was studied in A549 and CCRF-CEM cells. The cells were pretreated with DMSO $(10 \mathrm{mM})$ and C-PTIO $(20 \mu \mathrm{M})$ and co-cultured with cells which had been directly exposed to BLM and NCS. Pre-treatment of control bystander cells did not alter the baseline MN frequency. Pretreated bystand- er A549 cultures displayed an attenuation of bystander response at low concentration of BLM $(40 \mu \mathrm{g} / \mathrm{mL})$ and NCS $(0.5 \mu \mathrm{g} / \mathrm{mL})$; however, this reduction was statistically insignificant $(\mathrm{P}>0.05)$. Alternatively in CCRF-CEM cells, the pre-treatment of bystander cells with DMSO, reduced the MN frequency significantly $(\mathrm{P}<0.001)$ in bystander cells co-cultured with BLM exposed cells (40 and $80 \mu \mathrm{g} / \mathrm{mL}$ ) as well as NCS exposed cultures $(0.5 \mu \mathrm{g} / \mathrm{mL}$ and $2 \mu \mathrm{g} / \mathrm{mL})$. Whereas, the pre-treatment with C-PTIO did not show any decrease in $\mathrm{MN}$ frequency $(\mathrm{P}>0.05)$ in bystander cells, except $80 \mu \mathrm{g} / \mathrm{mL}$ BLM bystander cells (Fig. 3A and B).

\section{Expression of COX-2 in cells exposed to BLM, NCS and their respective bystander cells}

To find out molecular mechanisms mediating the bystander effect, the COX-2 level was measured in CCRF-CEM and A549 cells exposed to BLM or NCS. The COX-2 expression was higher in the BLM directly exposed cells when compared to that of NCS. The bystander cells (A549 and 


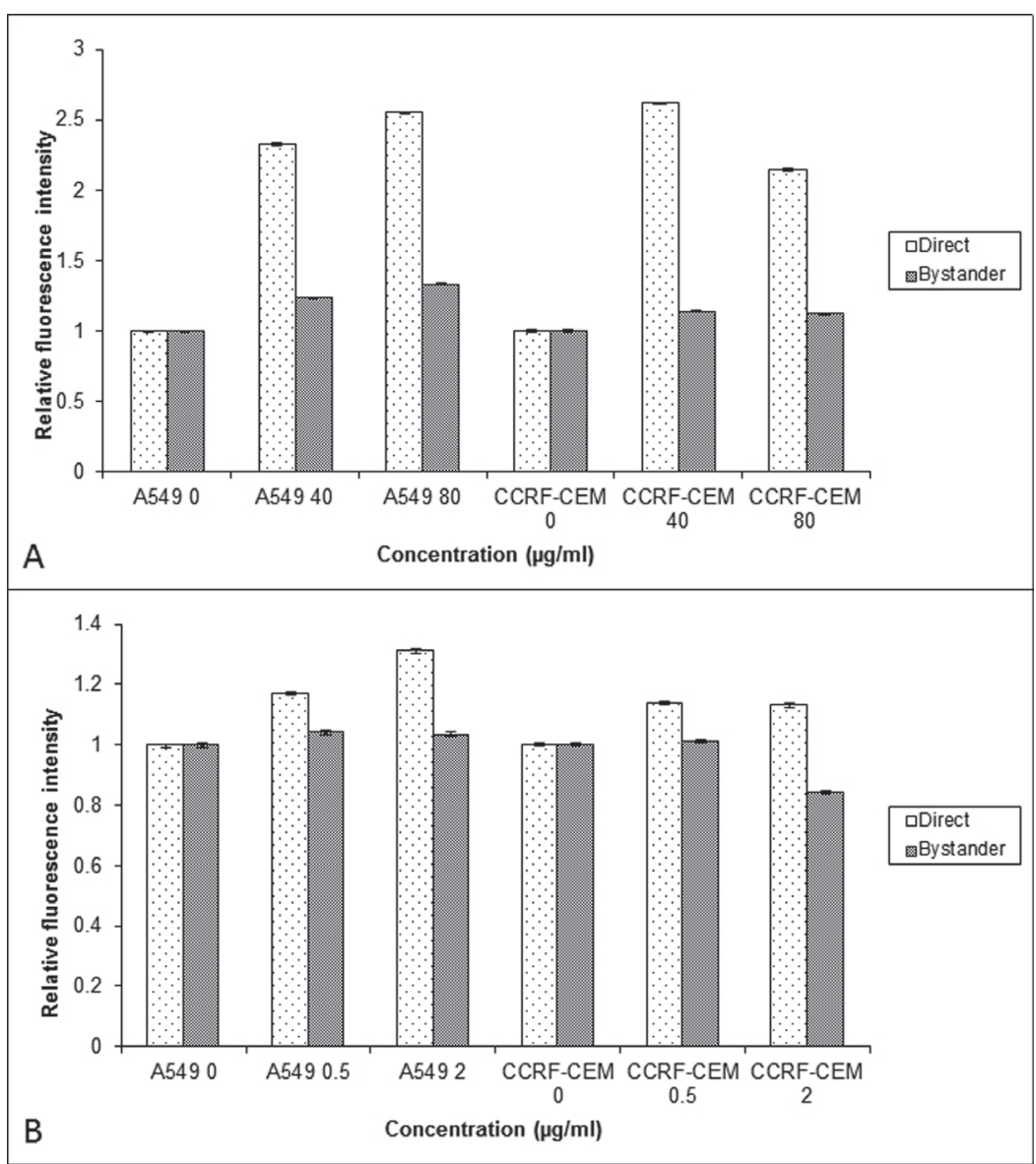

Figure 4. Comparison of the COX-2 relative fluorescent intensity obtained using flow cytometry in the A549 and CCRF-CEM cells that are exposed to BLM (A) and NCS (B) and then co-cultured with their respective bystander cells for 24 hrs. Each bar represents the mean \pm SE of the relative fluorescence intensity induced for three independent experiments $(n=3)$.

CCRF-CEM) co-cultured with BLM exposed cells showed increased expression of COX-2 when compared to their control ( $\mathrm{P}<0.001)$ (Fig. 4A). In contrast, no increased expression of COX-2 was observed in the bystander cells exposed to NCS treated cells $(\mathrm{P}>0.05)$ (Fig. 4B).

\section{Discussion}

Chemotherapy and radiotherapy are commonly used in the treatment of cancer with the use always based on the rationale of risk against benefit. Though, generally the benefits outweigh the risks in cancer therapy, there is a raised concern on the increased incidence of therapy induced second malignancy. Second malignancies, after radiotherapy [20] or combined radio and chemotherapy [21] are seen more frequently in younger individuals compared to adults, which has now become the leading cause of death among 15 year survivors of lymphoma. Alkylating chemotherapy has been shown to cause a large relative risk of leukemia within a few years after treatment. Similarly, risks from solid tumors increase more gradually, but in the long term, these cancers constitute the great majority of second malignancies, and the extent of these risks and their etiology are incompletely understood. Hence both radiotherapy and chemotherapy are themselves carcinogenic and second malignancy after treatment is important to characterize and prevent.

We speculate that an increased risk of second cancer may in part reflect the induction of genome destabilizing mutations in bystander cells due to non-targeted effects of therapeutic agents, as it has been shown that radiation and chemotherapeutic agents can induce bystander effects and genomic instability [22]. Involvement of ROS appears to be common to both, radiation induced genomic instability and bystander effect [23]. Hence, we investigated the role of ROS and NO in lymphoblastoid and lung adenocarcinoma cells of human origin, in mediating BLM and NCS induced bystander effects. The CCRF-CEM cells were selected as they are T-lymphoblast like cells constantly in circulation (suspension culture), which would help to evaluate the bystander effect induced by the drugs in these cells and its role in causing second malignancies. A549 cells are lung adeno- 
carcinoma cells, which are widely used in in vitro models to assess the DNA damage caused by radiation and chemotherapy. Further, BLM and NCS are radiomimetic drugs which induce damage by the formation of free radicals leading to the formation of DNA adducts and are used in the treatment of Hodgkins lymphoma [24], lung cancer and liver cancer [25]. Our results have shown that BLM and NCS induced a bystander response in CCRF-CEM and A549 cells, which was evidenced by the enhanced $\mathrm{MN}$ frequency and relative fluorescence intensity of $\gamma \mathrm{H} 2 \mathrm{AX}$ foci, measured in the bystander cells (Fig. 1 and 2). Additionally, we observed that the drugs BLM and NCS could not induce a bystander response in promyelocytic leukemic cells (HL-60). This could be attributed to the p53 status, cell survival or due to the high repair capacity, which might confer the characteristics of radio-resistance on them [26]. Furthermore, it was shown that mitochondria play a significant role in both mediating and regulating the bystander effect [27]. The fact that HL-60 cells are devoid of functional mitochondria provides an alternative reason as to why these cells were not able to induce bystander response like lymphoblast and lung adenocarcinoma cells [19].

The enhanced DNA damage induced in the bystander cells could be due to two reasons; first, it may be due to the presence of residual drug in the medium of exposed cells and the second being the bystander response mediated by soluble molecules. While the first was eliminated by HPLC studies, showing below detectable amounts of residual drug in the medium and cell lysate [14], the latter was studied using inhibitors of ROS and NO, as both were shown to be involved in mediating the bystander response. Indeed, ROS are capable of forming DNA damage and DNA single stranded breaks, which, if not repaired, could be converted to DNA double strand breaks upon collision with the replication fork in S-phase of the cell cycle [28]. NO for example has been proposed to be responsible, at least in part, for bystander effect signal propagation, as it is small, lipophilic, and capable of diffusing freely into cells. Therefore to explore the role of ROS and NO in mediating bystander effects, the free radical scavengers DMSO or C-PTIO were used respectively. Pretreatment of bystander cells with DMSO or C-PTIO did not alter the base-line $\mathrm{MN}$ frequency showing that concentrations of scavengers used are not toxic to the cells used in the study.

Consistent with ROS, involvement of NO in mediating the ionizing radiation induced bystander response [29] has been previously reported. Irradiated conditioned medium transfer experiments in $\mathrm{HaCaT}$ cell line, showed that ROS, $\mathrm{NO}$ and calcium were all found to be important signaling molecules involved in bystander responses, while ROS and calcium were found to be involved in the production of the bystander signal. However, in A549 cultures, pre-treatment with radical scavengers attenuated the magnitude of bystander response significantly in bystander cells at low concentra- tion and at higher concentration neither DMSO nor C-PTIO altered the magnitude of bystander response. Alternatively, in CCRF-CEM cells, while the pre-treatment of bystander cells with DMSO, reduced the MN frequency significantly in bystander cells, pre-treatment with C-PTIO, did not show any decrease in $\mathrm{MN}$ frequency in bystander cells, $10 \mathrm{mM}$ of DMSO may not be sufficient to scavenge the ROS generated by high doses of BLM in A549 cells, but it may be effective in CCRF-CEM cells, suggesting that there must be a cell type dependent variation in response to BLM exposure and the resultant release of bystander molecules. Similar results were observed by Shao [30], where DMSO reduced helium 3 induced bystander responses in both skin fibroblast and human glioblastoma cells, but C-PTIO reduced the bystander response only in skin fibroblast cells. In contrast, C-PTIO was found to attenuate the X-irradiated bystander effect, which DMSO failed to do [31]. Whereas in our study, C-PTIO reduced only BLM induced bystander response in A549 and CCRF-CEM cells, it did not in the NCS induced bystander effect in both the cell types. This result was further supported by the COX-2 expression done using flow cytometry, where increased expression of COX-2 was found in BLM exposed cells but not in NCS exposed cells. The observations that (i) NO is known to regulate the expression of IL-8 in some human cells [32] and (ii) NO synthase, which is critical to the biosynthesis of peroxynitrite anions, has been shown to be involved in the regulation of COX-2 expression [33] provide a functional link for the role of $\mathrm{NO}$ and COX-2 in mediating the bystander effect. Hence it can be noted that like radiation, chemotherapeutic drugs also induce bystander response and the signaling mechanism for the observed bystander response may be dependent on the cell type. This difference in mechanisms between cells may allow potential exploitation of bystander responses if these are observed in tissue systems. Mechanistic control of the bystander effect could either reduce radiation damage and potential carcinogenesis in normal tissues by reducing bystander signaling or maximize cell sterilization during radiotherapy by amplifying bystander responses in tumors. Taken together, these results expand on current paradigms of inheritance by showing that intercellular interactions can lead to a heritable increase in cellular susceptibility to recombination and suggest that past insults can lead to long-term changes in the risk of denovo homologous recombination events. If these observations are generally true within normal human tissues, then a single acute exposure to a cancer chemotherapeutic could potentially increase the risk of tumorigenic sequence rearrangements long after the initial exposure.

\section{Acknowledgment}

The authors sincerely acknowledge the financial assistance from Department of Science and Technology, Government 
of India (SR-SO/HS-77/2005).

\section{Financial Assistance}

Department of Science and Technology, Government of India (SR-SO/HS-77/2005).

\section{References}

1. Azzam EI, de Toledo SM, Little JB. Oxidative metabolism, gap junctions and the ionizing radiation-induced bystander effect. Oncogene. 2003;22(45):7050-7057.

2. Belloni P, Latini P, Palitti F. Radiation-induced bystander effect in healthy $\mathrm{G}(\mathrm{o})$ human lymphocytes: biological and clinical significance. Mutat Res. 2011;713(1-2):3238.

3. Hu B, Wu L, Han W, Zhang L, Chen S, Xu A, Hei TK, et al. The time and spatial effects of bystander response in mammalian cells induced by low dose radiation. Carcinogenesis. 2006;27(2):245-251.

4. Pasi F, Facoetti A, Nano R. IL-8 and IL-6 bystander signalling in human glioblastoma cells exposed to gamma radiation. Anticancer Res. 2010;30(7):2769-2772.

5. Gow MD, Seymour CB, Ryan LA, Mothersill CE. Induction of bystander response in human glioma cells using high-energy electrons: a role for TGF-beta1. Radiat Res. 2010;173(6):769-778.

6. Shareef MM, Cui N, Burikhanov R, Gupta S, Satishkumar S, Shajahan S, Mohiuddin M, et al. Role of tumor necrosis factor-alpha and TRAIL in high-dose radiationinduced bystander signaling in lung adenocarcinoma. Cancer Res. 2007;67(24):11811-11820.

7. Shao C, Lyng FM, Folkard M, Prise KM. Calcium fluxes modulate the radiation-induced bystander responses in targeted glioma and fibroblast cells. Radiat Res. 2006;166(3):479-487.

8. Poon RC, Agnihotri N, Seymour C, Mothersill C. Bystander effects of ionizing radiation can be modulated by signaling amines. Environ Res. 2007;105(2):200-211.

9. Matsumoto H, Tomita M, Otsuka K, Hatashita M, Hamada N. Nitric oxide is a key molecule serving as a bridge between radiation-induced bystander and adaptive responses. Curr Mol Pharmacol. 2011;4(2):126-134.

10. Hei TK. Cyclooxygenase- 2 as a signaling molecule in radiation-induced bystander effect. Mol Carcinog. 2006;45(6):455-460.

11. Zhou H, Ivanov VN, Lien YC, Davidson M, Hei TK. Mitochondrial function and nuclear factor-kappaB-mediated signaling in radiation-induced bystander effects. Cancer Res. 2008;68(7):2233-2240.

12. Asur RS, Thomas RA, Tucker JD. Chemical induction of the bystander effect in normal human lymphoblastoid cells. Mutat Res. 2009;676(1-2):11-16.

13. Jin C, Wu S, Lu X, Liu Q, Qi M, Lu S, Xi Q, et al. Induction of the bystander effect in Chinese hamster V79 cells by actinomycin D. Toxicol Lett. 2011;202(3):178-185.

14. Chinnadurai M, Chidambaram S, Ganesan V, Baraneedharan U, Sundaram L, Paul SF, Venkatachalam P. Bleomycin, neocarzinostatin and ionising radiation-induced bystander effects in normal diploid human lung fibroblasts, bone marrow mesenchymal stem cells, lung adenocarcinoma cells and peripheral blood lymphocytes. Int J Radiat Biol. 2011;87(7):673-682.

15. Rugo RE, Almeida KH, Hendricks CA, Jonnalagadda VS, Engelward BP. A single acute exposure to a chemotherapeutic agent induces hyper-recombination in distantly descendant cells and in their neighbors. Oncogene. 2005;24(32):5016-5025.

16. Gerashchenko BI, Howell RW. Cell proximity is a prerequisite for the proliferative response of bystander cells co-cultured with cells irradiated with gamma-rays. Cytometry A. 2003;56(2):71-80.

17. Fenech M, Holland N, Chang WP, Zeiger E, Bonassi S. The HUman MicroNucleus Project--An international collaborative study on the use of the micronucleus technique for measuring DNA damage in humans. Mutat Res. 1999;428(1-2):271-283.

18. Kataoka Y, Bindokas VP, Duggan RC, Murley JS, Grdina DJ. Flow cytometric analysis of phosphorylated histone $\mathrm{H} 2 \mathrm{AX}$ following exposure to ionizing radiation in human microvascular endothelial cells. J Radiat Res. 2006;47(3-4):245-257.

19. Alexandre J, Hu Y, Lu W, Pelicano H, Huang P. Novel action of paclitaxel against cancer cells: bystander effect mediated by reactive oxygen species. Cancer Res. 2007;67(8):3512-3517.

20. Sigurdson AJ, Jones IM. Second cancers after radiotherapy: any evidence for radiation-induced genomic instability? Radiat Res. 2005;163(6):702-703.

21. Hassaballa HA, Cohen ES, Khan AJ, Ali A, Bonomi P, Rubin DB. Positron emission tomography demonstrates radiation-induced changes to nonirradiated lungs in lung cancer patients treated with radiation and chemotherapy. Chest. 2005;128(3):1448-1452.

22. Limoli CL, Kaplan MI, Corcoran J, Meyers M, Boothman DA, Morgan WF. Chromosomal instability and its relationship to other end points of genomic instability. Cancer Res. 1997;57(24):5557-5563.

23. Lorimore SA, Coates PJ, Wright EG. Radiation-induced genomic instability and bystander effects: inter-related nontargeted effects of exposure to ionizing radiation. Oncogene. 2003;22(45):7058-7069.

24. Asakura H, Hori M, Umezawa H. Characterization of bleomycin action on DNA. J Antibiot (Tokyo). 1975;28(7):537-542.

25. Povirk LF. DNA damage and mutagenesis by radio- 
mimetic DNA-cleaving agents: bleomycin, neocarzinostatin and other enediynes. Mutat Res. 1996;355(12):71-89.

26. Jiang H, Li W, Li X, Cai L, Wang G. Low-dose radiation induces adaptive response in normal cells, but not in tumor cells: in vitro and in vivo studies. J Radiat Res. 2008;49(3):219-230.

27. Rajendran S, Harrison SH, Thomas RA, Tucker JD. The role of mitochondria in the radiation-induced bystander effect in human lymphoblastoid cells. Radiat Res. 2011;175(2):159-171.

28. Lombard DB, Chua KF, Mostoslavsky R, Franco S, Gostissa M, Alt FW. DNA repair, genome stability, and aging. Cell. 2005;120(4):497-512.

29. Shao C, Stewart V, Folkard M, Michael BD, Prise KM. Nitric oxide-mediated signaling in the bystander response of individually targeted glioma cells. Cancer
Res. 2003;63(23):8437-8442.

30. Shao C, Folkard M, Michael BD, Prise KM. Bystander signaling between glioma cells and fibroblasts targeted with counted particles. Int J Cancer. 2005;116(1):45-51.

31. Harada T, Kashino G, Suzuki K, Matsuda N, Kodama S, Watanabe M. Different involvement of radical species in irradiated and bystander cells. Int J Radiat Biol. 2008;84(10):809-814.

32. Xiong Q, Shi Q, Le X, Wang B, Xie K. Regulation of interleukin- 8 expression by nitric oxide in human pancreatic adenocarcinoma. J Interferon Cytokine Res. 2001;21(7):529-537.

33. Landino LM, Crews BC, Timmons MD, Morrow JD, Marnett LJ. Peroxynitrite, the coupling product of nitric oxide and superoxide, activates prostaglandin biosynthesis. Proc Natl Acad Sci U S A. 1996;93(26):1506915074. 